\title{
On the Added Value of Firm Valuation by Financial Experts
}

\author{
Dan Elnathan \\ School of Business \\ The College of Management \\ Rishon Lezion 75190, Israel \\ E-mail: danel@colman.ac.il \\ Ilanit Gavious (Corresponding author) \\ Guilford Glazer School of Business and Management \\ Ben-Gurion University \\ PO Box 653, Beer-Sheva 84105, Israel \\ Tel: 972-8-6477538Ｅ-mail: madaril@bgu.ac.il
}

\author{
Shmuel Hauser \\ ONO Academic College and Guilford Glazer School of Business and Management \\ 104 ZAAL st., Kiryat ONO 55000, Israel \\ E-mail: shauser@ono.ac.il
}

The authors thank Roni Amichai, Simon Beninga, Oded Sarig, seminar participants at the ISA, Ramy Elitzur, Gus De Franco, Phil Shane, Sanjai Bhagat, Gitit Gur-Gershgoren and seminar participants at the University of Colorado, Boulder, for their helpful comments.

\begin{abstract}
This paper is motivated by the recent concern raised by the SEC and other Securities Commissions around the Globe that financial analysts are not impartial. The question addressed is whether expert valuations provide unbiased information to shareholders and other stakeholders, and contribute to full disclosure. We examine the added value of expert valuations and their relationship to insider holdings based on a unique sample of 44 closely held companies listed on the TASE that were appraised by financial experts for transactions outside of the Exchange. These valuations are part of the full disclosure requirements in the case of extraordinary transactions. Each expert valuation is assessed on the basis of pre- and post-valuation data. Our key findings are: (1) expert valuations are $29 \%$ higher than market values and significantly affected by insider holdings; (2) there is a systematic upward bias in cash flow and cost of capital figures projected by experts; (3) expert valuations are not impartial; while they are supposed to provide an independent expert opinion, they are in fact biased towards majority shareholders who hired them to value the firm; (4) in the short-run investors respond cautiously to expert valuation; in the long-run, however, the over-valuation appears to be followed by destruction of value that is related to the firm's ownership structure.
\end{abstract}

Keywords: Insider holdings, Firm valuation, Financial experts, Insiders

\section{Introduction}

A recent IOSCO (International Organization of Securities Commissions) press release notes that securities analysts play an important role in global markets by helping investors make sense about information of publicly traded companies. However, these securities analysts are frequently "sell-side" analysts and therefore were criticized in many countries because conflict of interests can potentially bias their research and recommendations. According to Jensen (2005), in many cases when managers chose to defend unjustified overvaluation of their firm they ended up destroying part or all of the core value of the firm. (Note 1) 
Valuation of companies represent the "state of the art" in modern finance and accounting because of the need to resolve theoretical and empirical problems related to the analysis of financial statements, estimation of the cost of capital and prediction of future cash flows. Extant research does not thoroughly examine the whole range of factors that influence the valuation results (see, e.g., Bowers, 2002). In this paper we use a unique sample of 44 closely held firms listed on the Tel Aviv Stock Exchange (TASE) that were valuated by financial experts and for which a comprehensive data set was carefully gathered. (Note 2)

The purpose of the paper is to examine the added value of expert valuations of companies that were performed in the course of transactions such as mergers, acquisitions and private placements. In such cases, the Israel Securities Authority (ISA - Israeli SEC) requires a full disclosure of the transaction including a justification for the price of transaction to take place if it differs from market price. Customarily, majority shareholders that are on the sell or buy side of the transaction commission an expert valuation to justify the transaction price. The need for such non-routine expert valuations is often argued to be driven by management's perception that full disclosure (argued by some to simply be sophisticated data manipulation) of the procedure underlying the transaction would justify the price agreed upon for the transaction. Also, it appears that management considers the expert valuation as a hedge against possible litigation by outside shareholders. Both arguments rely on an implicit assumption that the experts performing such valuations are impartial, have superior information, and possess better capabilities to interpret it. These assumptions are examined in the study.

We question the benefits of such valuations of firms as part of the full disclosure requirements in the case of extraordinary transactions, under the notion of an efficient market hypothesis. (Note 3) Following the concern raised by IOSCO, the main hypothesis raised in this study is that these experts are not impartial; while they are supposed to provide an independent expert opinion, they seem to be, in fact, biased towards majority shareholders who hired them to value the firm.

The study expands on the existing literature. Its principal contributions lie in the comprehensive examination of a broad range of factors that influence the valuation results, including insider holdings and specific factors that characterize the company being valuated. For that purpose, each of the 44 firm valuations was examined meticulously, including use of alternative valuation methods and a retroactive analysis based on actual data, using the Discounted Cash Flows (DCF) method.

The paper proceeds as follows. Section 2 contains our literature review and Section 3 outlines the research design. In Section 4 we present the data. The first important finding is that, on average, expert valuations of companies are $29 \%$ higher than their stock market values.

In Section 5, we examine the hypothesis that the discrepancy between expert valuation and market value depends mainly on insider holdings. We also examine whether the discrepancy is influenced by the identity of the parties involved in the transaction, expert's reputation, the sector in which the company operates, firm size, share's liquidity and market trend. The main finding is that the discrepancy is primarily influenced by insider holdings and by the identity of the party to the transaction that commissioned the valuation.

In Section 6, we examine the hypothesis that the added value of expert valuations lies in their ability to obtain the required information (including inside information) from the company, and use it competently in their valuations. Our tests include reconstruction of expert valuations, where we employ the DCF method ex-post, using the realized cash flows and cost of capital for years subsequent to the valuation date. This allows us to test directly the forecasting errors experts made in their prediction of the company's future cash flows and cost of capital. The main findings are: (1) a systematic upward bias in the experts' estimated cash flows and cost of capital; and (2) on average, the value obtained by the experts was about $50 \%$ higher than ex-post value calculated based on realized cash flows and cost of capital. These results reject the hypothesis that experts possess superior information or capabilities to interpret it. On the other hand, the findings seem to support the claim that the added value of valuations for outside shareholders is limited, and that such valuations are intended mainly to appraise the value of the firm for the majority shareholders involved in the transaction. Thus, expert valuations do not seem to provide public shareholders and other stakeholders with unbiased information that contributes to full disclosure of such transactions as per ISA requirements. Based on these findings, we consider the observed price premium ( $29 \%$ divergence) to be "control premium". This conclusion gains further support in Section 7.

In Section 7, we examine the impact of expert valuations on share prices. Despite the $29 \%$ discrepancy between companies' expert valuations and their market value, on average, share prices did not change on the days surrounding the publication of valuation results. We find, however, that the change in share price depends on the size of the discrepancy and on share's liquidity, suggesting that outside investors react cautiously to the valuation results. This may indicate that outside investors are aware of the fact that the added value reflects primarily control premium. We also find support to Jensen's (2005) claim that unjustified overvaluation of firms contributes to the destruction of their values in the long-run. 
Summary and conclusions are presented in Section 8. The various findings are consistent with the findings of DeAngelo (1990), and of other studies, that transactions such as takeovers, mergers and acquisitions are generally made at a price different from the prevailing market price. The findings cast doubt on the objectivity of financial experts and therefore on the benefits of expert valuations as part of the full disclosure requirements.

\section{Literature review}

Many of the studies dealing with the valuation of companies relate to routine valuations of companies whose shares are traded on the exchange (e.g., O'Brien, 1998; De Bondet and Thaler, 1990; Lim, 2001). These valuations are performed regularly by "sell-side" analysts employed by investment banks as part of their services to clients. Unlike these studies, we focus on expert valuations commissioned by interested parties (buyers or sellers) as part of the process required for execution of transactions that take place outside the exchange.

Additional studies focus on several important aspects of valuations such as the role of accounting data (e.g., Givoly and Hayn, 2000; Barth et al., 1998; Francis and Schipper, 1999); models for equity evaluation (e.g., Ohlson, 1995; Ang and Liu, 2001); the use of multiples (Liu et al., 2002); and governance structure premium (e.g., Smith and Amoako-Ado, 1995; Hauser and Lauterbach, 2004). Many of these issues have been addressed in DeAngelo (1990). She investigates the discrepancy between the market value of companies and their intrinsic value in corporate control transactions. The latter usually takes place according to a value significantly different from market value (e.g., Comment and Jarrell, 1987; DeAngelo et al., 1984). DeAngelo (1990) finds that corporate control transactions have premiums of 50\%+ above pre-offer stock price. Brigham and Gapenski (1996), for comparison, report average premium of about $30 \%(20 \%)$ in hostile tender offers (friendly mergers). They also report buyouts with premiums ranging from $60 \%$ to over $100 \%$. According to DeAngelo (1990), a company's market value differs from its intrinsic value because the former is based on market assessment of managers' inside information, and not on the actual inside information that managers have; hence the need for independent expert valuations. However, according to DeAngelo (1990) there is a snag. Some claim that these experts are "rubber stamps" to a price already determined by the company's directors.

The methods used to value public companies include discounted cash flows (DCF), multiples of market price to accounting information, net asset value, and market value based on comparable transactions. According to DeAngelo (1990), despite its prominence in the finance literature, the DCF method is not the only one that is being used because it has several weaknesses. The main weakness lies in the method's sensitivity to assumptions regarding future profitability and the cost of capital. In their valuations, the experts may assign a greater weight to management's (relative to their own) estimates of future cash flows and cost of capital. DeAngelo argues that in order to increase the objectivity of their valuations, financial experts are supposed to base their analyses also on data obtained from external sources and avoid using a single valuation method. Specifically, she examines which valuation methods were used by four different experts who provided fairness opinions for corporate control transactions. She finds significant discrepancies between values obtained according to different methods of valuation, and that the results of DCF are highly sensitive to the assumptions regarding the terminal value. These issues are being examined here. The paper expands on DeAngelo's 1990 study and others. It contributes to the literature by systematically examining a whole range of factors that influence the experts and their valuation results, as well as exploring the added value of these expert valuations.

\section{Research methodology}

In the first phase of the study, we examine the effect of a broad range of factors on the discrepancy between the company's expert valuation and its market value. We employ specific factors that characterize the valuated company (size, industry, corporate governance), factors related to the transaction for which an expert valuation was commissioned (type of transaction, transaction with insiders vs. transaction with outsiders), factors related to the expert valuation itself (valuation method, expert's reputation), and market factors (market trends). We then seek to investigate whether the demand for expert valuations of closely held companies stems from the need to value the control premium for the majority shareholders involved in the transaction. To that end, we perform Theil's analysis of variance by forming two groups of variables: (1) corporate governance (represented by the percentage holdings of insiders and a dummy variable for transactions with current insiders); (2) firm's-specifics variables that characterize the company, the transaction and the market at time of transaction - valuation method, industry sector, size, market trend, trading volume and expert's reputation.

In the second phase of the study, we move to explore whether the discrepancy between expert valuations and market values derives also from the superior ability of experts to obtain information and use it competently. We estimate experts' prediction errors based on the differences between predicted and realized free cash flows (FCF) and cost of capital for each company during the five years following the expert valuation. Then, we use these figures to compare the value obtained by the expert to that obtained by reconstruction of the companies' value using DCF method. Calculation of realized FCF for each of the five years subsequent to the expert valuation is shown in Appendix. Starting in the sixth year we estimate a normalized level of FCF that would grow at a constant rate to perpetuity. (Note 4) 
The normalized level of FCF is determined based on four different alternatives: (1) FCF in the fifth year; (2) average FCF in the fourth and the fifth year; (3) average FCF in the third, fourth and fifth year (4) average FCF in all five years. All FCFs used to calculate the normalized level of free cash flows are adjusted as follows: cash flows from discontinued operations are deducted; investments in fixed assets are adjusted to the amount of depreciation and amortization in those years; and investments in working capital are adjusted to the long-term growth rate. (Note 5) The realized cost of capital was estimated based on the Capital Assets Pricing Model (CAPM), as CAPM is the model used by the experts in their valuations. (Note 6)

Weights of equity and debt for the calculation of cost of capital are based on the company's average capital structure during the five years following the disclosure of the expert valuation. Systematic risk was estimated using the market model in three ways: (1) estimate of industry $\beta$ versus the market; (2) assuming that $\beta=1$; and (3) estimate of the company's $\beta$ versus the market. In addition, we used the cost of capital employed by the expert in his valuation. $\beta$ was estimated based on share prices and the corresponding share indices, in the five years following publication date of the expert valuation. Discounting the firm's free cash flows at the firm's cost of capital results in the firm's value of operation (the enterprise value). To obtain the equity value we added the firm's non-operating assets and deducted its financial liabilities, as valuated by the experts. (Note 7)

The third stage of the analysis investigates whether and how investors in the stock market are influenced by expert valuations. We use an event study methodology to examine investors' response to the publication of expert valuation reports. We estimate the abnormal returns using the market model, $\varepsilon_{i t}=R_{i t}-\alpha_{i}-\beta_{i} R_{m t}$, where $R_{i t}$ is the rate of return on day $\mathrm{t}$ for firm $\mathrm{i}, R_{m t}$ is the rate of return on day $\mathrm{t}$ of the market index, and $\varepsilon_{i t}$ is the abnormal return for firm i on day t. $\alpha$ and $\beta$ are estimated using transaction data for the 210 trading days up to 30 days prior to the announcement day of the transaction for which the expert valuation was commissioned. In order to examine the effect of expert valuation on share prices around the time the valuation was publicized ("Day 0"), we calculated the average abnormal return and the average cumulative abnormal return for the period starting 30 days preceding the date of publication and ending 30 days following that date. We also examine to what extent the abnormal returns are influenced by the publication of expert valuation reports and the degree of share liquidity. The range of 30 days preceding publication was determined because during the process of preparing the reports of the prospective transactions and expert valuations to the ISA and the TASE, corrections and clarifications are frequently required before it is released to the public. Thus it is expected that if such influence on share prices exists, it will be present during the period directly preceding the publication. Finally, from a long-term perspective, we calculate abnormal returns in the 3 years that followed the date the expert valuation was published. To test the hypothesis raised by Jensen (2005) that there are agency costs attached to firms that are substantially overvalued, we examine the effect of ownership structure (insider holdings) on the extent of market value destruction throughout the years subsequent the expert valuation.

\section{Data}

The sample includes all 44 valuations that were performed by financial experts for firms whose shares have been acquired during the period of 1991 through 1999. Specifically, these valuations were related to 23 mergers and acquisitions and 21 private placements. The data include the documented valuations submitted by the valuator to the person or body who commissioned it. The documents generally contain all the details needed for the valuation: the company's industrial sector; the purpose of the valuation (the transaction for which the valuation was commissioned); the parties involved in the transaction and the nature of their relationship prior to and after the transaction; whether the transaction is with majority shareholders; and, who commissioned the valuation (buyer or seller). We also include a variable to indicate the expert's reputation, proxied by a dummy variable that equals ' 1 ' if the valuation was performed by one of three experts that together performed over $50 \%$ of the valuations in the sample, and at least three valuations each. The dummy variable equals ' 0 ' if it was performed by an expert that provided no more than two valuations in the sample. In addition, we examine the assumptions, analyses and forecasts employed by the experts in their valuations; the method or methods of valuation employed and the values obtained according to each method; the final value that was determined for the company and the method or methods selected to determine it; and sensitivity tests of the results obtained.

We also draw information from the financial statements published by the companies, starting from the year in which the valuation took place and continuing in each of the five following years. These figures serve to estimate, ex post, the forecasting errors made by the experts.

The market value and trading volume of the companies' shares are extracted from trading guides published by the TASE and the ISA. Missing data is taken from Predicta Ltd. Market value and trading volume are calculated on the basis of the average share price and shares' trading volume, during the 90 trading days prior to the date of valuation. To test the robustness of the results we also estimate market price based on the five days preceding the valuation date.

In order to identify the exact date on which the results of the expert valuations were disclosed to the public, we collected the immediate reports submitted by the companies to the TASE, the ISA and the press regarding the 
transaction for which the valuations were commissioned. These reports are required by law and have to be filed with the authorities immediately following significant events concerning the transactions. This information was found at the TASE library and from the database in the Yif'at Capital Disk Co.

Finally, we used the ISA database of daily share prices, general share index and the sector index of the valuated company, starting a year prior to publication of valuation results and ending five years following that date. These figures are used for the event study to examine investors' response to the valuation results, and for estimating, ex post, the experts' forecasting errors of firms' cost of capital.

\section{Insert Table 1}

Table 1 describes the results of the expert valuations in the sample. The main finding is that the value of companies as calculated by the experts is $29 \%$ higher than their market value $(M V(-90))$. This result does not change when market value is estimated on the basis of average share prices during the five days prior to publication date of the valuation results $(M V(-5))$. The difference between $M V(-90)$ and $M V(-5)$ is insignificant (p-value=0.963). (Note 8)

We also calculate a weighted average of the discrepancy between expert valuations and market values, using size (total assets) weights. Remarkably, the result remains unchanged (a $28 \%$ discrepancy). We point out that in only $23 \%$ of the cases, the expert valuation was lower than the market value of the company. Specifically, we find that in 34 cases, expert valuations were $46.0 \%$ higher than firms' market values, on average, compared with 10 cases in which expert valuations were $29.8 \%$ lower than firms' market values. Of the latter 10 cases, 9 were commissioned by insiders-buyers.

It should also be emphasized that in almost all of the 44 transactions, the actual price of the deal was identical to that of the expert valuations. More specifically, in 43 out of the 44 expert valuations, the transaction price was equal to the expert valuation. In one case, the transaction price was $6.5 \%$ lower than the expert valuation (57 compared with 61 millions of NIS). Hence, these valuations were the ending point when they were reported to the public, rather than the starting point, for the negotiations between the parties selling and those buying. In other words, since the expert valuation is meant to provide justification for the transaction price, his preliminary valuation is, in fact, indirectly part of the negotiations and he or the parties involved may change their final valuation prior to reporting it to the public. This finding was also observed by DeAngelo (1990) who argued that financial experts rely too heavily on the information gathered from insiders. (Note 9)

In the following section we shall examine the factors that influence the valuation results, including the effect of insider holdings and specific factors related to the valuated company.

\section{Factors that may influence the discrepancy between companies' expert valuation and market value}

In this section we examine the hypothesis that the discrepancy between the company's expert valuation and its market value is a function of specific factors that characterize the valuated company, including insider holdings. Table 2 presents the results.

\section{Insert Table 2}

The first finding is that the discrepancy between expert valuation and market value does not depend on the valuation method used by the expert, the industrial sector in which the company operates, expert's reputation, size of the company, transaction type or market trends. Notably, when we differentiated between the results of valuations that relied on a single method (DCF, net asset value, comparable transactions of other firms, or multiples), and the results of valuations that were obtained from averaging the results of several methods, the discrepancies in the latter were significantly lower ( $p$-value $=0.081$, not tabulated) than those obtained by a single method. This finding is consistent with DeAngelo's (1990) claim that experts' objectivity requires them to rely on more than one method in their valuations.

When relating valuation results to market trends, the differences - though insignificant - indicate that the discrepancy between expert valuation and market value is larger (smaller) when the market is trending downwards (upwards). We also analyze the results according to the expert's reputation. Although there is no statistically significant difference between the results, we find that for the more reputable experts, the discrepancy in the valuations was lower (24\%) relative to the group of 13 experts who performed a total of 24 valuations (32\%). A possible explanation is the tendency of the former to base their valuations on more than one method whereas the latter usually do with one.

The most important finding concerns the influence of insider holdings on the discrepancy between expert valuation and market values. The results indicate that in companies where the holdings of majority shareholders are relatively high (higher than the median), the discrepancy between expert valuation and market values is approximately $37 \%$, compared with $21 \%$ in companies where the holdings of majority shareholders is relatively low ( $\mathrm{p}$-value $=0.07$ ). This finding raises the possibility that the need for expert valuation stems from the need to appraise the firm's value for the majority shareholders involved in the transaction, and as such, these valuations are not intended for outsiders; i.e., outsiders should not be affected by the expert valuations in their decision making. We shall see below that share prices did not increase in response to the experts' upward estimated value suggesting that the added value of the expert valuations is in 
appraising the premium of control that is not necessarily reflected in the price observed in the market. Thus, investors in the market seem to realize that the valuations are aimed at the majority shareholders that are involved in the transactions. This explanation gains further support from the fact that the bias in expert valuations is greater in transactions involving insiders-sellers with outsiders than in transactions involving private placements to insiders-buyers. In transactions with insiders-buyers the bias was (13.2\%) and significantly lower (p-value=0.045) than in transactions involving insiders-sellers $(47.5 \%)$. This finding is mainly affected by who commissioned the valuation. It appears that smaller bias in transactions involving private placements to insiders is when these insiders-buyers commissioned the valuation and the larger bias in transactions involving insiders-sellers with outsiders is when the insiders-sellers commissioned the expert valuation. (Note 10) These findings also support DeAngelo's (1990) claim that financial experts rely too heavily on the information gathered from those insiders.

At this stage, we further examine the hypothesis that the demand for expert valuations of closely held companies stems from the need to value the control premium for the majority shareholders involved in the transaction. This premium reflects, inter alia, the additional value that majority shareholders are willing to pay for the ability to control the company's activities (Hauser and Lauterbach (2004)). In such cases, an expert valuation is required if share prices in the market do not include the control premium. The market value may include control premium if investors consider the possibility of future contests for control that may lead to a demand for their voting rights by the parties interested in acquiring control of the company. According to Smith and Amoako-Ado (1995), the higher the probability investors attribute to such event, the higher the control premium embedded in the shares' market price. In Israel, because of the prevailing concentrated insider holdings of closely held firms, there are almost no such contests for control and therefore the control premium finds expression only in transactions with insiders (Hauser and Lauterbach (2004)) and in transactions with outsiders who acquire control of the company.

To estimate the overall impact of insider holdings together with other variables that characterize the company under valuation, we perform Theil's analysis of variance by forming two groups of variables. Insider holdings are represented by the percentage holdings of insiders and a dummy variable for transactions with current insiders, which is assigned the value of 1 when the transaction was with an insider on the buy-side and 0 otherwise. In the second group we include firm's-specifics variables that characterize the company and the transaction - valuation method, industry sector, size, market trend, trading volume and expert's reputation.

\section{Insert Table 3}

The results, presented in Table 3, indicate that the discrepancy between expert values and market values is significantly affected by insider holdings. We find that this discrepancy is smaller for insiders-buyers. As a robustness check, we repeat the Theil's analysis without grouping the control variables. In this setting of multivariate framework the relative importance of the key individual variables is assessed, as these variables may not be independent. The results obtained are qualitatively the same.

The findings are consistent with the assumption that share prices in the market reflect their value to the marginal investor, who trades on the exchange but who is not involved in any other aspect of the firm's activity. The results also correspond to the findings of Hauser and Lauterbach (2004) that the value of voting rights derives mainly from their value to majority shareholders. We tend to conclude, therefore, that expert valuations are primarily intended for majority shareholders and not for outside shareholders. This finding gains further support in the following sections.

\section{Does the added value of the experts derive from their superior information about companies?}

In this section, we examine the hypothesis that the discrepancy between expert valuations and market values derives also from the superior ability of experts to obtain information and use it competently. According to DeAngelo (1990) this discrepancy may be due to the difference between market expectations and management expectations regarding future cash flows. Hence, the added value of expert valuators depends to a large extent on their ability to gain complete access to inside information from the company and to use it efficiently.

We estimate experts' prediction errors based on the differences between predicted and realized free cash flows and cost of capital for each company during the five years following the expert valuation. Then, we use these figures to compare the value obtained by the expert to that obtained by reconstruction of the companies' value using DCF method.

\section{Insert Table 4}

Table 4 presents the forecasting errors of cash flows and cost of capital, based on a partial sample of 15 expert valuations that used the DCF method. The results show that the cash flow estimates have an upward bias compared to the actual figures. In all years, the realized cash flows were consistently smaller than those estimated by the experts. Specifically, about $50 \%$ of the companies valuated had negative cash flows, compared to the forecasted positive cash flows, indicating a systematic bias in the forecasts. It is possible, however, that the results simply indicate that the experts do not have an advantage over other investors in obtaining or utilizing more efficiently the information disclosed to the public. It should also be noted here that one seemingly drawback of this analysis is the fact that it relies 
on relatively small number of observations and that the entire market was surprised by the poor ex-post performance. We argue that overwhelming evidence that in practically all years the cash flows were biased upwards shadows this drawback of our analysis, particularly when combined with the all other results reported in the paper.

The results of Table 4 also show that forecasted cost of capital is biased upward. (Note 11) The bias in the cost of capital estimate may reflect the ambiguity with which the experts regard their own forecasts. However, since expert valuations were higher than market values, we shall see below that the influence of the upward bias in cash flow estimates was dominant.

We turn now to calculating the realized value of all 44 companies in the sample at the time the expert's valuation was published. The valuations were reconstructed for each company on the basis of the realized cash flows and cost of capital $\left(\mathrm{V}_{\text {REALIZED }}\right)$. The results of these valuations were compared to the expert valuations $\left(\mathrm{V}_{\text {EXPERT }}\right)$. Table 5 displays the results.

\section{Insert Table 5}

We find that the realized value is about $50 \%$ lower than the value of the companies as calculated by the experts. Specifically, more than half of the companies had negative cash flows in the five years subsequent to the expert valuation. In these cases we assigned zero to the company's value. The results reject DeAngelo's (1990) hypothesis that the discrepancy between expert valuation and market value can be explained by the superior information that the experts possess and their ability to use it competently. These findings cast doubt on either the experts' objectivity or their superior ability in appraising the value of public firms.

\section{The impact of expert valuations on share prices}

\subsection{A Short-Term Perspective}

Are investors in the stock market influenced by expert valuations? If DeAngelo (1990) is correct in claiming that there is a discrepancy between the expectations of the market and those of management, than share prices are expected to change if investors recognize the superior ability of the experts to forecast companies' future cash flows and cost of capital.

\section{Insert Table 6}

Table 6 displays cumulative abnormal returns (CAR) surrounding the publication date of the expert valuations. We find that CAR is insignificantly different from zero indicating that, on average, investors did not respond to information revealed when expert valuations were disclosed to the market, in spite of the $29 \%$ divergence between the expert valuation and the market values of the companies. This finding is consistent with the findings presented earlier. They may be regarded as another piece of evidence to support the hypothesis that the expert valuations are aimed at estimating the control premium for the majority shareholders involved in the transaction. As such, they are not intended for outside shareholders, those not part of the control group, who limit their investment decisions to trading on the exchange. Our finding that there was no significant change in share prices around the time of publication of expert valuations, combined with the finding of a systematic upward bias in the expert valuations - and with the experts' bias being particularly towards majority shareholders who hired them to value the firm - seem to suggest that the outside shareholders recognize that expert valuations are of limited importance to them since they are aimed at the parties involved in the transactions. This leads us to conclude that the above mentioned discrepancy may be interpreted as "control premium".

In order to test whether share prices are influenced by the size and direction of the discrepancies between expert valuation and market values, and the degree of share liquidity (Amihud and Mendelsohn, 1987), we estimated the following regression equation:

$$
\text { CAR }(-30,30)=-0.0534+0.01658 \frac{V_{\text {EXPERT }}}{M V}-0.0084 \text { Volume } \quad R^{2}=0.173
$$

$$
\begin{array}{llll}
(\mathrm{p} \text {-value }) \quad(0.081) \quad(0.003) \quad(0.032)
\end{array}
$$

Equation (1) reveals, as expected, that the cumulative abnormal return is higher when the discrepancy between expert valuation and market value is greater, and the liquidity of the stock is lower. Indeed, we find that when discrepancy between expert valuation and market value exceeds $29 \%$, CAR $(-30,30)=5.21 \%$ compared with CAR $(-30,30)$ $=-7.86 \%$ when this discrepancy is lower than $29 \%$ (the difference is significant at 0.02 level). The influence of liquidity on share price is related, inter alia, to the possibility that for thinly traded shares, whose market value may not reflect their "true" economic value, investors attribute greater importance to expert valuations. (Note 12) 


\subsection{A Long-Term Perspective}

In this subsection we test the hypothesis raised by Jensen (2005) that there are agency costs attached to firms that are substantially overvalued since managers may fail to deliver the performance required to support that value. In such cases, market disappointment results in firm's value destruction. According to Jensen (2005) the problem lies, to a large extent, in the insider holdings system. To test this hypothesis we estimated the change in market values over the years. In Table 7, we present evidence that supports the hypothesis. Market values appear to decline by over $50 \%$ in the 3 years that followed the date the expert valuation was published. Prior studies on long-run underperformance for mergers and acquisitions document either negative or insignificant long-term abnormal returns (see, for example, Loughran and Vijh, 1997; Sudarsanam and Mahate, 2003; Conn et al., 2005; Alexandritis et al., 2006). Whereas the lowest returns documented in these studies reach around $-20 \%$ three years from the time of transaction, in our study negative abnormal returns for the same period reach around $-56 \%$. We conclude that our finding of long-term underperformance is only partially related to the underperformance effect typical to transactions such as mergers and acquisitions. Notably, most of the underperformance presented in Table 7 seems to be related to value destruction that is explained by agency costs attached to overvalued firms (Jensen, 2005).

We also estimated a regression model to examine the effect of ownership structure on the extent of market value destruction. We find,

$$
\begin{array}{lll}
C_{\text {CA,3-years }}= & -1.258+0.963 \text { Insider_Holdings } & R^{2}=0.087 \\
(\mathrm{p} \text {-value }) & (0.011) & (0.052)
\end{array}
$$

where, $C A R_{0,3-\text { years }}=\ln \frac{M V_{3} \text {-years }}{M V(-90)}-\ln \frac{S_{j}}{S_{0}}$, is the percentage change in market values minus the general share index return in the 3 years that followed the publication of the valuation. The positive coefficient seems to suggest that the more closely-held is the firm, the lower is the value destruction (higher CAR). However, given that in most of our sample firms (40/44), insiders hold more than $50 \%$ of the firm's equity, the results suggest that in firms in which insiders holdings are in the lower $50 \%$, the value destruction is higher. One possible explanation is that the interests of insiders who have a higher (lower) percentage of holdings are more (less) aligned with those of outside shareholders. In the former firms, insiders have higher control but their motivation to expropriate firm's assets is lower than in the latter firms since they represent the vast majority of shareholders. Indeed, we find that in the 22 firms with the highest holdings of insiders, $85 \%$ on average, $C A R_{0,3 \text {-years }}=-38.5 \%$, whereas in the other 22 firms, in which insiders' holdings were $59 \%, C A R_{0,3-y e a r s}=-73.4 \%$, on average. Hence, it appears that insider holdings have significant effect on firms' value destruction.

\section{Insert Table 7}

\section{Summary and conclusions}

The difficulty in valuating companies stems from the need to deal with conceptual and empirical issues that relate to financial statements' analysis, expectations regarding the companies' profitability, and their cost of capital. In this study we examine the added value of expert valuations of closely-held companies whose shares are listed on the TASE and whose insider holdings is typical to most firms listed in European and Asian exchanges, and small firms in the US. The empirical work is based on a comprehensive data set of 44 companies that were valuated for transactions carried out outside the exchange. Each expert valuation was thoroughly examined, including the use of alternative methods to those employed by the experts, and by post factum reconstruction of the data.

The principal findings are that the discrepancy between expert valuations and market values is $29 \%$ and that insider holdings are the dominant factor explaining this discrepancy. The discrepancy does not depend on the valuation method and the industry sector of the company. We also find that despite the size of the discrepancy, on the average, share prices did not change significantly following the publication of expert valuation results. These findings correspond to the findings of DeAngelo(1990) that in corporate control transactions, share prices agreed upon for the transactions usually differ from the market price of the company. The results gain farther support from the ex-post analysis of valuations, where we find that the experts systematically bias upwards their estimates of future cash flows and cost of capital. We also find that the ex-post values of the companies valuated were $50 \%$ lower than the value determined in the expert valuation. The fact that there is no significant change in share prices around the time of publication of expert valuation results, combined with the finding of a systematic upward bias in the expert's valuation, seem to suggest that in the short-run outside investors recognize that expert valuations are of limited importance to them since they are 
aimed at the parties involved in the transactions. In the long-run, however, we find that firms that were overvalued by experts, lost on average over $50 \%$ of their values supporting Jensen's argument that when managers cannot deliver the performance required to justify firms' value, disappointed investors appear to destruct firms' value. These findings cast doubt on the ability of experts to be objective and therefore on the benefits of expert valuations as part of the full disclosure requirements.

\section{References}

Alexandridis, G., Antoniou, A., \& Zhao, H. (2006). Valuation effect of institutional ownership: the case of corporate takeovers. European Financial Management, 12 (3).

Amihud, Y., \& Mendelson, H. (1987). Trading Mechanisms and Stock returns: An Empirical Investigation, Journal of Finance, 42, 533-553.

Ang, A., \& Liu, J. (2001). A General Affine Earnings Valuation Model. Review of Accounting Studies, 6 (4), 397-425.

Barth, M.E., Beaver, W.H., \& Landsman, W.R. (1998). Relative Valuation Roles of Equity Book Value and Net Income as a Function of Financial Health. Journal of Accounting and Economics, 25, 1-34.

Benninga S. Z., \& Sarig O.H. (1997). Corporate Finance: A Valuation Approach. McGraw- Hill.

Bowers, H.M. (2002). Fairness Opinions and the Business Judgment Rule: An Empirical Investigation of Target Firms. Northwestern University Law Review, 96 (2), 567-578.

Brigham, E.F., \& Gapenski, L.C. (1996). Intermediate Financial Management. (5 $5^{\text {th }}$ ed.). The Dryden Press, Orlando, Florida.

Comment, R., \& Jarrell, G.A. (1987). Two-Tier and Negotiated Tender Offers: The Imprisonment of the Free-Riding Shareholder. Journal of Financial Economics, (December), 283-310.

Conn, C., Cosh, A., Guest, P., \& Hughes, A. (2005). The impact on UK acquirers of domestic, cross border, public and private acquisitions. Journal of Business Finance and Accounting, 32, 815-870.

De Bondt, W.F.M., \& Thaler R.H. (1990). Do Security Analysts Overreact? American Economic Review, 80 (May), 52-7.

DeAngelo, H., DeAngelo, L., \& Rice, E.M. (1984). Going Private: Minority Freezeouts and Stockholder Wealth. Journal of Law and Economics, (October), 367-401.

DeAngelo, L.E. (1990). Equity Valuation and Corporate Control. The Accounting Review, (January), 93-112.

Francis, J., \& Schipper, K. (1999). Have Financial Statements Lost Their Relevance? Journal of Accounting Research, 37, 319-352.

Givoly, D., \& Hayn, C. (2000). The Changing Time-Series Properties of Earnings, Cash Flows and Accruals: Has Financial Reporting Become More Conservative? Journal of Accounting and Economics, (29), 287-320.

Hauser, S., \& Lauterbach, B. (2004). The Value of Voting Rights to Majority Shareholders: Evidence from Dual Class Stock Unifications. Review of Financial Studies, 17 (4), 1167-1184.

Jensen, S.C. (2005). Agency Costs of Overvalued Equity. Financial Management, 34 (1), 5-19.

Kaplan, S.N., \& Ruback, R.S. (1995). The Valuation of Cash flows Forecasts: An Empirical Analysis. Journal of Finance, 50 (4), 1059-1093.

Lim, T. (2001). Rationality and Analysts' Forecast Bias. Journal of Finance, LVI (1), 369-385.

Liu, J., Nissim, D. \& Thomas, J. (2002). Equity Valuation Using Multiples. Journal of Accounting Research, 40 (1), 135-172.

Loughran, T., \& Vijh, A.M. (1997). Do long term shareholders benefit from corporate acquisitions? Journal of Finance, 52, 1759-1790.

O`Brien, P.C. (1998). Analysts' Forecasts as Earnings Expectations. Journal of Accounting and Economics, 10, 53-58.

Ohlson, J. A. (1995). Earnings, Book Value and Dividends in Security Valuation. Contemporary Accounting Research, 11, 661-687.

Smith, B., \& Amoako-Ado, B. (1995). Relative Prices of Dual Class Shares. Journal of Financial and Quantitative Analysis, 30, 223-239.

Sougiannis, T., \& Yaekura, T. (2001). The Accuracy and Bias of Equity Values Inferred From Analysts' Earnings Forecasts. Journal of Accounting, Auditing and Finance, 16 (Fall), 331-362.

Sudarsanam, S., \& Mahate, A.A. (2003). Glamour acquirers, method of payment and post-acquisition performance: the UK evidence. Journal of Business Finance and Accounting, 30, 299-341. 


\section{Notes}

Note 1. In announcing the publication of the principles for addressing analyst conflict of interests, US SEC commissioner, Roel C. Campos, stated: "IOSCO members understand that investor confidence is fundamental to strong, healthy financial markets. When investors come to believe that analysts offering supposedly independent research are really little more than marketers for investment bank, this confidence suffers."

Note 2. The sample represents a norm in most countries since many small firms in the US, and most publicly traded firms outside of US, are closely held by a small group of majority shareholders.

Note 3. In 2001, the ISA considered prohibiting the use of expert valuations in such cases but did not apply it eventually.

Note 4. The normalized level of FCF is needed for calculation of a firm's terminal value. We conduct sensitivity analyses for the firms' expected growth rate for perpetuity using various growth rates from $0 \%$ to $4 \%$ (see Sougiannis and Yaekura (2001)). We report here only the results based on 2\% growth. The results are essentially the same when other growth rates are used.

Note 5. The normalized flow of investments in fixed assets is supposed to be at least as large as the depreciation and amortization expenses (See Kaplan and Ruback, 1995). Also, the investment in working capital should be adjusted to the growth rate to perpetuity, which is typically lower than the growth rate during the years for which the estimation is carried out. We test and find that using actual free cash flows, without adjusting to investments in fixed assets and working capital, (but instead assuming that the investment amounts in the years following the expert valuation are representative), does not change the results qualitatively.

Note 6. See Beninga and Sarig (1997), pp. 297-301.

Note 7. The value of non-operating assets and financial liabilities can theoretically be estimated using discounted cash flows, but typically the non-operating assets are estimated using their market (realization) value and financial liabilities are estimated using their book value. We do not calculate the economic value of the financial liabilities, but rely on the expert valuation, since we do not have the detailed maturity dates of the liabilities for the sample companies. Additional adjustments to the realized equity value include deduction of the value of minority interests and a discount for holdings companies. The discount for holdings companies is taken based on the discount rate estimated by the experts. The value of minority interests is calculated as follows. In case that the subsidiary company was (not) separately evaluated by the experts, we calculate the value of minority interests as the product of the minority's percentage holdings and the expert value (market value) of the subsidiary company. In case that the subsidiary company is neither traded on the exchange nor it was evaluated by the experts, we estimate its value based on an average of the values obtained by multiplying the company's reported earnings before extraordinary items (book value of equity) by the earnings (book value) multiple in its industrial sector.

Note 8 . The date of publication was on average 50 days following the announcement of the up-coming transaction. This may explain why both $M V(-90)$ and $M V(-5)$ include investors' response to the transaction itself.

Note 9. It should be noted that whenever an extraordinary transaction is considered, the ISA requires a full disclosure on the nature of the transaction and the way the price was determined. As a result, in all such transactions, in practice, at least one of the parties involved hires an expert to provide a valuation that justifies the transaction price. Usually that party will be an interested party (holding at least $5 \%$ of the company's shares). Since the ISA examines the expert valuation, and often times makes comments on that valuation which may actually lead to changes in the valuation, the transaction price agreed upon by the parties is reported to the public together with the final valuation. As a result, almost always the transaction price will be in line with the expert's valuation. Since the expert valuation is meant to provide justification for the transaction price, he is, in fact, indirectly part of the negotiations. In fact, often he will be invited to the ISA together with the selling and buying parties to respond directly to the inquiries of the ISA officials. Hence, the valuation made by the expert is an important benchmark for the transaction price that will eventually be agreed upon by the parties involved. Notably, since the ISA may address questions to the expert and may consider asking for another expert's opinion, the expert is supposed to be committed to an objective valuation. This "objective" valuation is the subject of investigation in this paper. In rare cases, these valuations are not reported to the public, if the expert valuation did not justify the transaction price and the deal was called off by the parties involved.

Note 10. Outsiders commissioned only 9 valuations.

Note 11. The results do not change qualitatively when we estimate the cost of capital in other ways, among them: estimating $\beta$ against industry index or assuming that $\alpha=0, \beta=1$.

Note 12 . We examined the possibility that other variables representing company characteristics also influence share prices, and did not find such influence. 
Table 1. Discrepancy between expert values and market values

\begin{tabular}{|c|c|c|c|}
\hline & Mean & Median & SD \\
\hline$V_{\text {EXPERT }}$ & 945 & 92 & 2318 \\
\hline$M V$ & 818 & 71 & 2188 \\
\hline$B V$ & 521 & 61 & 1260 \\
\hline$\%$ holdings of majority shareholders & 0.723 & 0.715 & 0.177 \\
\hline \multirow[t]{2}{*}{$\operatorname{Ln}\left(V_{\text {EXPERT }} / M V(-90)\right)$ - simple average } & 0.288 & 0.269 & 0.431 \\
\hline & $(0.000)$ & $(0.000)$ & \\
\hline \multirow[t]{2}{*}{$\operatorname{Ln}\left(V_{\text {EXPERT }} / M V(-5)\right)$ - simple average } & 0.279 & 0.273 & 0.392 \\
\hline & $(0.000)$ & $(0.000)$ & \\
\hline \multirow[t]{2}{*}{$\operatorname{Ln}\left(V_{\text {EXPERT }} / M V(-90)\right)$ - weighted average } & 0.280 & & \\
\hline & $(0.036)$ & & \\
\hline \multirow[t]{2}{*}{$\operatorname{Ln}\left(V_{\text {EXPERT }} / M V(-5)\right)$ - weighted average } & 0.270 & & \\
\hline & $(0.038)$ & & \\
\hline
\end{tabular}

The figures presented here are based on 44 valuations of companies listed on the TASE. V V EXPER represents the expert valuation. MV (-90) and MV (-5) represent the average market value during 90 and 5 trading days prior to the date of valuation, respectively, in millions of NIS. (During the sample period, FX rate was in the range of 2.2-4 NIS per 1 \$US). $\mathrm{BV}$ represents book value of equity. Values in brackets represent the p-value for the t-test (Wilcoxon test) that the mean (median) value differs significantly from zero. The discrepancy between expert's value and market value is measured by the percentage difference between $\mathrm{V}_{\text {EXPERT }}$ and MV. The percentage holdings by majority shareholders represent the total holdings of all interested parties. Among them are shareholders holding at least $5 \%$, management and directors, all required by law to report their holding to the ISA and the TASE. Weighted average uses Total Assets weights. 
Table 2. Factors influencing the discrepancy between market value and expert valuation

\begin{tabular}{ccc}
\hline No. Of & Mean & Median \\
Companies
\end{tabular}

By Valuation Method
Discounted Cash Flow (DCF)
Multiplies (P/E)
Net Assets Value
Market Value (MV)
Weighted Average of Various Valuation Methods
Test for the differences between means \& medians

$\begin{array}{ccc}12 & 0.344 & 0.406 \\ 3 & 0.398 & 0.346 \\ 15 & 0.383 & 0.298 \\ 6 & 0.267 & 0.244 \\ 8 & 0.076 & 0.136 \\ & (0.600) & (0.494)\end{array}$

\section{$\underline{B y}$ industry Sector}

Financial

3

0.109

0.364

Commerce and Services

Real Estate

9

0.173

0.244

7

0.474

0.463

Manufacturing

0.248

0.233

Investments and Holdings

0.345

0.273

Test for the differences between means \& medians

(0.611)

\section{By Size}

$$
\begin{aligned}
& \text { Large Companies } \\
& \text { Small Companies }
\end{aligned}
$$

Test for the differences between means \& medians

$(0.349)$

\section{By Transaction type}

Mergers and Acquisitions

Private Placements

Test for the differences between means \& medians

\section{By Market Trends}

Bull Market - until 1/94

Bear Market - since 1/94

Test for the differences between means \& medians

\section{By Expert's Reputation}

\section{More reputable \\ Less Reputable}

Test for the differences between means \& medians

\section{By Transactions with insiders}

Insiders in private placements

Insiders-sellers with outsiders

Test for the differences between means \& medians

\section{By percentage holdings of insiders}

Large

$\begin{array}{cc}0.365 & 0.347 \\ 0.211 & 0.256 \\ (0.070) & (0.097)\end{array}$

Test for the differences between means \& medians

In this table we present the discrepancy between Market Value (MV) and Expert Valuation $\left(\mathrm{V}_{\text {expert }}\right)$, in \%, by various categories. Values in brackets give the p-value to the t-test (or the Wilcoxon signed ranks test) for comparison between means (medians) of the different groups. In the categories of valuation methods and sector we used the ANOVA and Kruskall-Wallis test. The "high" and "low" categories are determined relative to the median value. The following 
hypotheses concerning the various variables were examined: (1) for firm size: the discrepancy is smaller for smaller firms; (2) for market trends: the discrepancy is smaller in a bull market; (3) for expert's reputation, the discrepancy is smaller for the more reputable experts relative to the less reputable experts; (4) for insider transactions: the discrepancy is larger in transactions with outsiders; (5) for holding percentage of insiders: the discrepancy is larger when majority shareholders have a larger holding percentage.

Table 3. Theil's analysis of variance of factors influencing the discrepancy between expert valuation and market value

$\begin{array}{cr}\begin{array}{c}\text { Explanatory Variables } \\ \text { Groups }\end{array} & \begin{array}{r}\text { Marginal Contribution of Each } \\ \text { Variance }\end{array} \\ \text { 1. Ownership Structure } & \begin{array}{r}\text { Proportion of Variance } \\ \text { F }\end{array} \\ \text { 2. Control Variables - Firm's specifics } & 0.160 \\ \text { F } & 8.006 \\ & (0.007) \\ & 0.289 \\ & 0.781\end{array}$

This table uses Theil's analysis of variance to examine the influence of insider holdings and specific company factors, on the discrepancy between expert valuation and market value, by computing and analyzing $\left(V_{\text {EXPERT }} / \mathrm{MV}\right)$. Lines $1-3$ represent the explanatory contribution of the group of variables to the total variance of the premium, discounting the influence of other explanatory variables. The calculation was done in three stages: (1) $R_{n}^{2}$ was calculated by running a linear regression between the dependent variable and all the independent variables; (2) $R_{n-h_{j}}^{2}$ was calculated by running a linear regression between the dependent variable and all explanatory variables except the variables $h_{j}$; $(3)$ Calculation of the relative contribution of a group of variables by subtracting $R_{h_{j}}^{2}$ from $R_{n}^{2}$. Line 4 is the $R_{n}^{2}$ of the linear regression between the price premium as the dependent variable and all explanatory factors. Line 3 is the difference between Line 4 and the sum of proportions in lines 1 and 2. The group of ownership structure contains a dummy variable for transactions with insiders-buyers and outsiders-sellers, which is assigned the value of 1 , and the value of 0 otherwise. In the second group we include control variables that characterize the company - valuation method, industry sector, size, market trend, trading volume and expert's reputation. Numbers in parenthesis are p-values. 
Table 4. Experts' forecasting errors in estimates of free cash flows and cost of capital

\begin{tabular}{|c|c|c|c|c|c|c|c|}
\hline & \multirow[t]{2}{*}{ Mean } & \multirow[t]{2}{*}{ SD } & \multirow[t]{2}{*}{ Minimum } & \multirow[t]{2}{*}{ Maximum } & \multicolumn{3}{|c|}{ Percentile } \\
\hline & & & & & $25 \%$ & Median & $75 \%$ \\
\hline & & & \multicolumn{5}{|c|}{ Forecasting Errors of Cash Flows } \\
\hline \multicolumn{8}{|c|}{$\underline{\text { Cash Flow in Year } 1}$} \\
\hline Forecast & 27605 & 77563 & -17414 & 303094 & 1183 & 7080 & 12900 \\
\hline Realized & 14573 & 82508 & -49205 & 305363 & -2552 & -67 & 8700 \\
\hline \multicolumn{8}{|c|}{$\underline{\text { Cash Flow in Year } 2}$} \\
\hline Forecast & 36485 & 108152 & 254 & 426316 & 1788 & 6291 & 20754 \\
\hline Realized & -12995 & 150228 & -477058 & 296125 & -17025 & -1300 & 19079 \\
\hline \multicolumn{8}{|c|}{ Cash Flow in Year 3} \\
\hline Forecast & 44561 & 13395 & 1290 & 526728 & 2336 & 6261 & 20754 \\
\hline Realized & -58929 & 298428 & -112877 & 158627 & -3289 & 3515 & 18771 \\
\hline \multicolumn{8}{|c|}{ Cash Flow in Year 4} \\
\hline Forecast & 65121 & 174928 & 1171 & 638421 & 2653 & 7840 & 22477 \\
\hline Realized & -46511 & 166125 & -598445 & 23200 & -9514 & -619 & 3043 \\
\hline \multicolumn{8}{|c|}{ Cash Flow in Year 5} \\
\hline Forecast & 84400 & 226199 & 1044 & 761582 & 4600 & 8639 & 20754 \\
\hline Realized & -7044 & 8742 & -21160 & 5050 & -14100 & -3192 & -360 \\
\hline \multicolumn{8}{|c|}{ Normalized Cash Flow from Year 6} \\
\hline Forecast & 82708 & 266501 & 618 & 1042008 & 3519 & 7557 & 13836 \\
\hline Realized, Method 1 & -64634 & 257789 & -995954 & 24300 & -3179 & 182 & 5334 \\
\hline Realized, Method 2 & -33330 & 137690 & -530258 & 20000 & -3210 & -195 & 8935 \\
\hline Realized, Method 3 & -7426 & 42459 & -158186 & 23000 & -2786 & 380 & 7767 \\
\hline Realized, Method 4 & 3978 & 6891 & -1290 & 20200 & -238 & 219 & 10489 \\
\hline
\end{tabular}

Forecasting Errors of Cost of Capital

$\begin{array}{lccccccc}\text { Forecast } & 0.100 & 0.022 & 0.060 & 0.150 & 0.080 & 0.100 & 0.115 \\ \text { Realized } & 0.084 & 0.035 & 0.040 & 0.180 & 0.060 & 0.070 & 0.105 \\ & (0.065) & & & & & (0.016) & \end{array}$

The Table presents comparison between realized free cash flows (FCF) and expert's forecasts based on the 15 expert valuations that used the DCF method. The FCF are in thousands of NIS. The normalized FCF starting from the sixth year was calculated in four alternative ways: (1) FCF during the preceding year; (2) Average FCF during the preceding two years; (3) Average FCF during the preceding three years; (4) Average FCF during the preceding five years. Figures in brackets represent the p-value for testing the hypothesis that there is no difference between the means (t-test) or between the medians (Wilcoxon test). Realized cost of capital is calculated using the CAPM model on the basis of data for the five years following date of publication of the report. Risk-free rate was estimated according to the average yields of government bonds of up to 10 years to redemption. 
Table 5. Forecasting errors in expert valuation based on ex-post data

Normalized Cash Flow according to

Preceding 1 Year $\quad \underline{\text { Preceding } 2 \text { Years }}$ Preceding 3 Years $\quad$ Preceding 5 Years

\begin{tabular}{|c|c|c|c|c|}
\hline & -0.500 & -0.424 & -0.423 & -0.540 \\
\hline $\ln \left(\frac{V_{\text {REALIZED }}}{V_{\text {EXPERT }}}\right)$ & $(0.006)$ & $(0.002)$ & $(0.002)$ & $(0.001)$ \\
\hline
\end{tabular}

The table is based on the reconstruction of the 44 valuations in the sample using the DCF method. The forecasting errors are calculated as the percentage divergence between the value determined by the expert (VEXPERT) and realized value (VREALIZED). Realized value of each company is calculated based on realized free cash flows during the five years following the publication of the expert valuation report, a normalized free cash flow starting from the sixth year, and the actual cost of capital of the companies. Actual cost of capital is calculated using the CAPM model on the basis of data for the five years following date of publication of the report. $\beta$ in the model is estimated on the basis of monthly data for the same period. Figures in brackets represent the p-value for the sign test that the median is significantly different from zero.

Table 6. Cumulative abnormal returns surrounding the publication date of the expert valuations

\begin{tabular}{cccccc}
\hline & \multicolumn{5}{c}{$T_{1}, T_{2}$} \\
& $-30,0$ & $-30,10$ & $-30,20$ & $-30,30$ & $-1,1$ \\
\cline { 2 - 6 } Mean & 0.0133 & 0.0057 & 0.0088 & -0.0116 & 0.0028 \\
p-value & $(0.58)$ & $(0.72)$ & $(0.16)$ & $(0.67)$ & $(0.77)$
\end{tabular}

The cumulative abnormal return (CAR) is calculated according to the market model estimated using share prices over a period of 180 days - 210 up to 30 trading days preceding the date of announcement of the transaction for which the valuation was commissioned. $T_{1}$ and $T_{2}$ represent the event window. Values in brackets represent the $p$-value for a t-test that examines the hypothesis that the mean is insignificantly different from 0.

Table 7. The impact of expert valuations on market values: a long-term perspective

\begin{tabular}{ccc}
\hline $\mathbf{J}=\mathbf{1}$ & $\mathbf{J = 2}$ & $\mathbf{J = 3}$ \\
\hline-0.204 & -0.403 & -0.559 \\
$(0.006)$ & $(0.000)$ & $(0.000)$
\end{tabular}

This Table presents the average excess returns (CAR) calculated as follows:

$$
C A R_{0,3-\text { years }}=\ln \frac{M V_{j}}{M V(-90)}-\ln \frac{S_{j}}{S_{0}}
$$

where $M V_{j}$ is firm's market value $\mathrm{j}$ years from the time the expert valuation was published, $\mathrm{j}=1,2,3, S_{j}$ is general stock index at time j. Numbers in parenthesis are p-values. 


\section{Appendix: Calculation of Free Cash Flows (FCF)}

The actual FCF that were used in Section 6 were calculated using the following procedure. Free cash flows are those generated by the operating activities of the company and are free for distribution to the debtors, owners of convertible securities, or shareholders. We calculate the free cash flows of the companies in Real terms (i.e. Adjusted to the CPI in the month of the valuation by the expert) based on the information in the financial statements, which were published in the periods following the valuation by the expert as follows:

Cash flows from operating activities (1)

+ Financing expenses, after tax (2)

$+/$ - Special items, after tax (3)

- Investments in Fixed Assets (4)

(1) Cash flows from operating activities are taken from the statement of cash flows in the financial statements.

(2) In an unlevered valuation, the enterprise (operating activity) and the debt are valuated separately. The value of the operating activities is calculated by discounting the cash flows from operating activities, that is - the net operating cash flows before financing expenses and the associated tax shield. Therefore, the financing items have to be isolated from the cash flows from operating activities. Besides the financing expenses that are required to pay for the financial obligations of the firm, financing revenues from financial assets are also isolated. The reason is that the financial assets are valuated separately from the operating activities and are included in the non-operating assets of the firm, or subtracted from its financial obligations.

(3) We also isolate from the cash flows from operating activities those cash flows stemming from revenues and expenses incurred not in the course of the ordinary operating activities of the firm (non-operating items) and special (extraordinary) items. We do not isolate cash flows from discontinued operations. Whether the expert predicted the discontinuation of the operations or not, it is still relevant to compare and contrast the expert's predictions regarding those operations to the actual results, just as we do for the continuing operations.

(4) From the cash flows from operations we subtract the cash flows used for investment in fixed assets that are necessary for continued operations. Those investments can be made in order to maintain current level of activity or in order to expand the operations and grow. Investments in fixed assets can also be made as the company is substituting labor with capital assets. When analyzing this item it is critical that we distinguish between assets that are being used in the operating activities of the firm and non-operating assets. At this stage only the first type is taken, since these assets are the ones that generate operating cash flows. By contrast, the investment in non-operating assets does not affect the operating results of the firm. Non-operating Assets usually include holdings in subsidiaries and affiliated companies, and real estate assets that are not used as part of the ordinary operating activities of the firm, but instead are held for development and/or resale in the future. The valuation of the non-operating assets is conducted separately from the valuation of the operating activities. In the event that these assets yield cash flows, we isolate these cash flows from the “cash flows from operating activities" item as part of the extraordinary items' adjustment (see (3) above). 